\title{
Influence of buccal corridor dimension on smile esthetics
}

\author{
Diana Cunha Nascimento', Êmeli Rodrigues dos Santos ${ }^{2}$, Andre Wilson Lima Machado ${ }^{3}$, Marcos Alan Vieira Bittencourt ${ }^{4}$
}

Objective: To assess the influence of buccal corridor width on smile esthetics of male and female, Caucasian and Afro-descendant subjects by means of digitally manipulated photographs, as well as compare assessments of full-face view (FFV) and closeup view of the mouth (CUVM) images. Methods: Facial photographs were taken of four adults' smile, two Caucasians and two Afro-descendants of both genders. The resulting images were digitally manipulated with the aim of rendering - from each original smile - three other smiles simulating three different buccal corridor widths, namely, narrow, medium width and wide. The rendered images, 12 of which portraying FFVs and 12 providing CUVMs, were assessed by 60 examiners who rated the attractiveness of each smile by means of a visual analog scale (VAS). The data were treated with ANOVA and Tukey's post test to compare the different buccal corridors, and Student's $t$ test to compare the two image views (FFV and CUVM). Results: Medium width buccal corridors were considered the most attractive in the four individuals investigated, both in the assessment of FFVs and CUVMs $(p<0.05)$. Comparison between the narrow and wide buccal corridors, in general, showed no statistically significant differences ( $p>0.05$ ). Furthermore, no statistically significant difference was found between the analyses of FFVs and CUVMs ( $>$ > 0.05). Conclusion: The buccal corridor exercised a remarkable influence on smile esthetics, with the medium width group being rated as the most attractive. No influence was exerted by the individuals' face, ethnicity or gender.

Keywords: Dental esthetic. Smile. Orthodontics.

Objetivo: avaliar a influência do corredor bucal na estética de sorrisos femininos e masculinos, de leucodermas e melanodermas, por meio de fotografias manipuladas, bem como comparar essa avaliação numa vista facial completa e numa vista aproximada da boca. Métodos: foram realizadas fotografias faciais do sorriso de quatro indivíduos adultos, sendo dois leucodermas e dois melanodermas, de ambos os sexos. As imagens geradas foram manipuladas a fim de produzir, a partir de cada sorriso original, três outros simulando gradações distintas de corredor bucal: estreito, médio e amplo. As imagens geradas, 12 retratando uma vista facial completa e outras 12 em vista aproximada da boca, foram avaliadas por um grupo de 60 examinadores, que indicaram, por meio de escalas visuais analógicas, o nível de atratividade de cada sorriso. Os dados foram submetidos aos testes estatísticos ANOVA e pós-teste de Tukey, para comparar os diferentes corredores bucais, e ao teste $t$ de Student, para comparar os dois tipos de enquadramento. Resultados: os corredores bucais médios foram considerados os mais atrativos nos quatro indivíduos pesquisados, tanto na avaliação completa da face quanto na vista aproximada do sorriso ( $<<0,05)$. Na comparação entre os corredores bucais estreitos e amplos, em geral, não houve diferença estatisticamente significativa ( $p>0,05)$. Além disso, também não houve diferença estatisticamente significativa entre a análise feita pelos dois tipos de enquadramento $(p>0,05)$. Conclusão: o corredor bucal exerceu forte influência na avaliação estética do sorriso, sendo o médio considerado o mais atrativo, não tendo havido influência da face, da etnia ou do sexo dos indivíduos.

Palavras-chave: Estética dentária. Sorriso. Ortodontia.

${ }^{1}$ Specialist in Orthodontics -Federal University of Bahia (UFBA).

${ }^{2}$ Specialista in Periodontics - Bahia State Dentistry Study Center (CEBEO/BA).

${ }^{3}$ Associate Professor, Orthodontics- UFBA; PhD in Orthodontics, UNESP/UCLA; MSc in Orthodontics PUC-MG; Collaborating Professor at the MSc program in orthodontics at UCLA.

${ }^{4}$ Associate Professor and Head of the Orthodontics Specialization Program - UFBA; Msc and PhD in Orthodontics - Federal University of Rio de Janeiro; Director of the Brazilian Board of Orthodontics.

How to cite this article: Nascimento DC, Santos ER, Machado AWL, Bittencourt MAV. Influence of buccal corridor dimension on smile esthetics. Dental Press J Orthod. 2012 Sept-Oct;17(5):145-50.
Submitted: Marh 31, 2012 - Revised and accepted: August 06, 2012

» The authors report no commercial, proprietary or financial interest in the products or companies described in this article.

» Patients displayed in this article previously approved the use of their facial and intraoral photographs.

Contact address: Marcos Alan Vieira Bittencourt

Av. Araújo Pinho, 62 - $7^{\circ}$ andar - Canela - Zip code: 40110-150 - Salvador/BA - Brazil E-mail:alan_orto@yahoo.com.br 


\section{INTRODUCTION}

The smile is the most primitive form of human communication. It enhances facial beauty and plays a part in defining the qualities and virtues of one's personality. ${ }^{1}$ Its impact, however, is not linked solely to the individual dental beauty. ${ }^{2}$ A pleasant smile depends directly - above and beyond the appearance of teeth and gums - on conformity with the standards of structural beauty, the relationship between teeth and lips and their integration into the facial composition. ${ }^{1}$

The smile characteristics regarded as the most important ones are: The smile arc, dental alignment, tooth color and shape, incisal edge regularity, amount of incisor and gum display, and buccal corridor. ${ }^{3-5}$ The buccal corridor concept emerged during the 50's out of concern with ensuring natural looking dentures. ${ }^{6,7}$ This aspect of smile esthetics, also called lateral dark space, lateral negative space or "shadow tunnel," constitutes the existing dynamic space that appears, when a person smiles, between the labial surface of maxillary posterior teeth and the inner mucosa of the soft tissues that form the corners of the mouth and the cheeks. ${ }^{1,6,8-10}$ This space arises from the dark background of the mouth, and depends on the shape and width of the upper dental arch and the facial muscles responsible for the breadth of the smile. ${ }^{11}$

Although some information on the ideal buccal corridor size is available in the literature, most of it is based on clinical opinions, whereas the scientific studies that addressed this issue yielded controversial outcomes. ${ }^{8,10,12-16}$ Several studies showed that broad smiles with narrower buccal corridors are seen as more attractive. ${ }^{13,14,16}$ On the other hand, other authors noted that buccal corridor width does not affect how the smile is judged from an esthetic viewpoint., $80,12,15$ Likewise, according to Isiksal et al, ${ }^{17}$ transverse characteristics seem to be of little significance in smile attractiveness. By the same token, some researchers argue that the lateral negative space influences smile esthetics only when it becomes excessively wide. ${ }^{15}$

Other issues related to this debate can also be found in the literature: The possibility that culture can influence esthetic perception, and the differences in perception between different genders and ethnicities. To illustrate this point, articles that investigated the esthetic influence of the buccal corridor used Caucasian women's smiles, ${ }^{8,10,12-16}$ thereby raising the question of whether these findings can be used to assess men's smiles and Afro-descendant individuals. Moreover, another issue relevant to the dispute is that esthetic preference for specific features may vary between individuals of different countries, ${ }^{18}$ which calls into question the use of esthetic parameters in places where the research has not been conducted.

The lack of consensus between results found in the literature, ${ }^{8,10,12-16}$ combined with the scarcity of data on the esthetic preference for male smiles and Afrodescendant individuals, and especially the absence of studies that reveal the esthetic preference of the Brazilian population demonstrates the need for further research in this area. Thus, the aim of this study was to assess the influence of buccal corridor width on smile esthetics of male and female, Caucasian and Afro-descendant subjects by means of digitally manipulated photographs, as well as to compare assessments of these photos in full-face view (FFV) and close-up view of the mouth (CUVM).

\section{MATERIAL AND METHODS}

Eight photographs were selected from the image databank of the Orthodontic Department of the School of Dentistry, Bahia State Federal University. Four of these images depicted a full-face view (FFV) and the other four, a close-up view of the mouth (CUVM) of four adult individuals, i.e., two Caucasian - one from each gender - and two Afro-descendants, also from both genders. The ethnicity of these individuals was characterized using the classification parameters established by the Brazilian Institute of Geography and Statistics (IBGE) (São Paulo State Health Secretariat/ USP/FSP, IBGE, 2000). Images were selected for exhibiting adequate dental alignment, proper display of the upper incisors on smiling, coincidence of the upper and lower midlines with the facial midline, and no apparent facial asymmetry.

After selection, the images were digitally manipulated using Adobe Photoshop 9.0 software (Seattle, Washington, USA). In order to standardize and render more accurate the analysis and changes, dental inclinations and gingival contours were corrected in all original photographs, and a near golden ratio was obtained in one half of the smile. This digitally manipulated half of the face was duplicated in order to become completely symmetric. 
Thereafter, the buccal corridor was changed in order to produce three widths: Narrow, medium width and wide. To define these standards, the distance between the outer commissures of each smile was measured and a space between the outer commissure and the labial surface of the last viewed maxillary molar was established. On the narrow buccal corridor this space was defined at $6 \%$ of the distance between the outer commissures, with $3 \%$ for each side; on the medium width corridor, $16 \%$, with $8 \%$ for each side; and on the wide corridor, $26 \%$, $13 \%$ for each side. During this second phase of digital manipulation only the tooth positions and their gingival margins were changed. The three images depicting the narrow, medium width and wide buccal corridors, at the two different views, of the Caucasian female can be seen in Figures 1 and 2 .

Two photograph albums were organized with the three images of each individual on the same page. One album comprised images showing each individual's full face whilst in the other album, the images in closeup view. Each photograph was randomly laid out on the pages as was the sequence of photographs of each individual in the album.
In order to assess the 24 images, a group of 60 judges -30 orthodontists and 30 laypersons with graduate degrees in different areas - was deployed. Raters were made aware of study goals and signed a free and informed consent form. Along with the albums, each examiner received a form comprising eight rulers (visual analog scale), ${ }^{10,13,19}$ one on each page, and were then requested to mark with a dot, identify the letter corresponding to the image, and rate each image according to their perceived attractiveness. Each judge was allowed to mark the dot anywhere on the ruler and place two or more letters at each dot, if necessary. The visual analog scale ${ }^{24,25,26}$ was $10 \mathrm{~cm}$ long and had "VERY BAD" written on the left end and "VERY GOOD" at the opposite end. The center of the ruler was marked with a dash to give raters a perception of "average." The distance (in $\mathrm{mm}$ ) between the rater's mark and the left end was measured with a Mitutoyo digital caliper, and served not only as a parameter for judging the attractiveness of each smile, but also constituted the actual rating assigned by each examiner.

The data were compiled and treated statistically. Kolmogorov-Smirnov test was employed to ascertain that
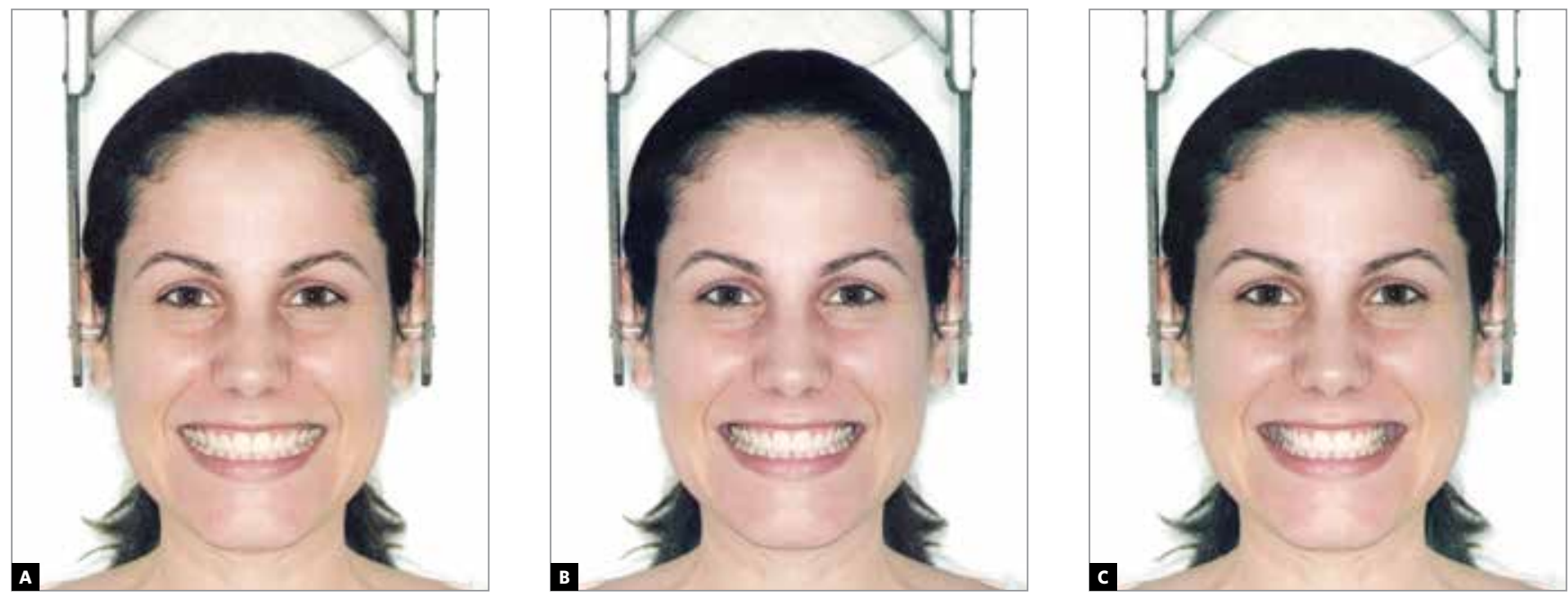

Figure 1 - Images of Caucasian woman's smile in full-face view, showing narrow (A), medium width (B) and wide (C) buccal corridors.
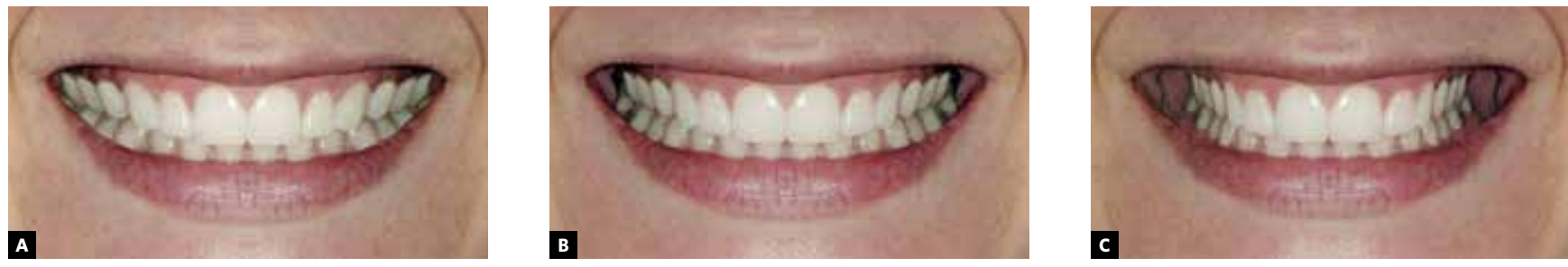

Figure 2 - Images of Caucasian woman's smile in close-up view of the mouth, showing narrow (A), medium width (B) and wide (C) buccal corridors. 
the sample had a normal distribution. Next, after establishing sample normality, ANOVA and Tukey's post test were used to compare the different widths of the buccal corridor, while Student's $t$ test was applied to compare the assessments made of FFV vs. CUVM images. A 95\% significance level was adopted in all analyses.

\section{RESULTS}

Tables 1 and 2 show the means and standard deviations of the level of attractiveness exerted by the different buccal corridor widths on the raters regarding the female and male smiles, respectively. In all cases, medium width buccal corridors were considered the most attractive ones $(\mathrm{p}<0.05)$. When comparing narrow vs. wide corridors, statistically significant differences arose on occasion, with narrow corridors showing superiority in the Afro-descendant woman in both views (FFV and CVVM), and in the Afro-descendant man, in FFV assessments ( $<<0.05)$.

Table 3 shows unpaired Student's $t$ test comparing assessments of full-face (FFV) images with close-up views of the mouth (CUVM). As can be seen, no statistically significant difference was found between these two types of assessment ( $p>0.05)$.

Table 1 - Means and standard deviations of the attractiveness levels of Caucasian and Afro-descendant women's smiles, according to different buccal corridor widths, in both image views (FFV and CUVM) (ANOVA and Tukey's post test).

\begin{tabular}{|c|c|c|c|c|c|c|c|}
\hline & \multirow{2}{*}{ Buccal corridor } & \multicolumn{3}{|c|}{ Caucasian Woman } & \multicolumn{3}{|c|}{ Afro-descendant Woman } \\
\hline & & Mean & SD & Results ${ }^{\star}$ & Mean & SD & Results* \\
\hline \multirow{3}{*}{ Close-up view (CUVM) } & A-Narrow & 49.03 & 27.81 & & 54.49 & 29.98 & \\
\hline & B-Medium & 75.90 & 22.97 & $B>A, C$ & 80.51 & 22.06 & $B>A>C$ \\
\hline & C-Wide & 38.12 & 24.39 & & 31.72 & 24.35 & \\
\hline \multirow{3}{*}{ Full-face view (FFV) } & A-Narrow & 47.73 & 27.88 & & 49.19 & 25.95 & \\
\hline & B-Medium & 72.24 & 23.32 & $B>A, C$ & 84.39 & 19.39 & $B>A>C$ \\
\hline & C-Wide & 35.81 & 25.00 & & 35.39 & 23.46 & \\
\hline
\end{tabular}

*Images with the same letter do not differ significantly $(p<0.05)$

Table 2 - Means and standard deviations of attractiveness levels of Caucasian and Afro-descendant men's smiles, according to different buccal corridor widths, in both image views (FFV and CUVM) (ANOVA and Tukey's post test).

\begin{tabular}{|c|c|c|c|c|c|c|c|}
\hline & \multirow{2}{*}{ Buccal corridor } & \multicolumn{3}{|c|}{ Caucasian Man } & \multicolumn{3}{|c|}{ Afro-descendant Man } \\
\hline & & Mean & SD & Results* & Mean & SD & Results* \\
\hline \multirow{3}{*}{ Close-up view (CUVM) } & A-Narrow & 44.51 & 27.91 & & 48.37 & 28.96 & \\
\hline & B-Medium & 75.06 & 22.69 & $B>A, C$ & 76.46 & 21.28 & $B>A, C$ \\
\hline & C-Wide & 43.50 & 25.39 & & 39.00 & 27.10 & \\
\hline \multirow{3}{*}{ Full-face view (FFV) } & A-Narrow & 49.15 & 26.06 & & 49.40 & 27.66 & \\
\hline & B-Medium & 72.10 & 24.30 & $B>A, C$ & 77.94 & 20.14 & $B>A>C$ \\
\hline & C-Wide & 40.96 & 27.56 & & 33.35 & 25.09 & \\
\hline
\end{tabular}

${ }^{\star}$ Images with the same letter do not differ significantly $(p<0.05)$.

Table 3 - Mean and standard deviation of attractiveness levels of male (M) and female (F) smiles, in close-up and full-face views (Student unpaired t test).

\begin{tabular}{|c|c|c|c|c|c|c|c|c|c|c|}
\hline & \multirow{2}{*}{ Buccal corridor } & \multicolumn{2}{|c|}{ Afro-descendant (M) } & \multicolumn{2}{|c|}{ Caucasian (M) } & \multicolumn{2}{|c|}{ Afro-descendant (F) } & \multicolumn{2}{|c|}{ Caucasian (F) } & \multirow{2}{*}{ Results } \\
\hline & & Mean & SD & Mean & SD & Mean & SD & Mean & SD & \\
\hline \multirow{3}{*}{ Close-up view } & Narrow & 48.37 & 28.96 & 44.51 & 27.91 & 54.49 & 29.98 & 49.03 & 27.81 & \multirow{6}{*}{$\begin{array}{c}\text { Close-up view } \\
= \\
\text { Full-face view } \\
\quad(p>0.05)\end{array}$} \\
\hline & Medium & 76.46 & 21.28 & 75.06 & 22.69 & 80.51 & 22.06 & 75.90 & 22.97 & \\
\hline & Wide & 39.00 & 27.10 & 43.50 & 25.39 & 31.72 & 24.35 & 38.12 & 24.39 & \\
\hline \multirow{3}{*}{ Full-face view } & Narrow & 49.40 & 27.66 & 49.15 & 26.06 & 49.19 & 25.95 & 47.73 & 27.88 & \\
\hline & Medium & 77.94 & 20.14 & 72.10 & 24.30 & 84.39 & 19.39 & 72.24 & 23.32 & \\
\hline & Wide & 33.35 & 25.09 & 40.96 & 27.56 & 35.39 & 23.46 & 35.81 & 25.00 & \\
\hline
\end{tabular}




\section{DISCUSSION}

The impact of buccal corridor width on the smile's esthetic perception is still controversial. Parekh et $\mathrm{al}^{5}$ argued that this feature does not contribute significantly to smile attractiveness. However, they included changes in the smile arc and lateral dark space in the same analysis. Johnson and Smith, ${ }^{8}$ and Gianelly ${ }^{12}$ compared the esthetics of the smile after treatment with and without extractions and found no differences. Roden-Johnson et $\mathrm{al}^{10}$ and Ritter et $\mathrm{al}^{15}$ corroborated these findings when reporting that buccal corridor does not influence the esthetic evaluation of smile photographs.

Unlike these findings and agreeing with Dunn et $\mathrm{al},{ }^{20}$ the results of this study demonstrated that varying buccal corridor widths significantly affected smile attractiveness. This influence was not affected by gender, coinciding with the findings of Moore et al, ${ }^{14}$ nor by ethnicity, as shown in Tables 1 and 2 . By the same token, these findings support the study of Tedesco et $\mathrm{al},{ }^{21}$ who found that ethnicity and gender do not interfere with the judgment of dentofacial attractiveness.

In all subject categories, the medium width buccal corridor - with a $16 \%$ distance between the outer commissures - was considered the most pleasant one. This result was similar to the one found by Gracco et al, ${ }^{4}$ who detected a preference for an image with buccal corridor equivalent to $18.46 \%$ of the width of the smile, and disagreed with Moore et al, ${ }^{14}$ who reported as more attractive a smile with a lateral negative space of $2 \%$. Such difference may have occurred as a result of the fact that in the study by Moore et $a,{ }^{20}$ the buccal corridor was measured based on inner commissures. Moreover, their method for changing the variable was different, i.e., the intercanine width was maintained while the number and width of the posterior teeth were modified.

A comparison between the narrow and wide buccal corridors after analyzing the four individuals studied showed greater predilection for the narrow buccal corridor in the Afro-descendant woman, in both views, and for FFV only in the Afro-descendant man. No other statistically significant difference was found between them. These findings disagrees with other studies in which broad smiles with narrow buccal corridors were considered more attractive., ${ }^{4,5,14,20}$ This divergence underscores the need for further studies involving esthetic parameters for Afro-descendant individuals, which was also noted by Suzuki et al. ${ }^{22}$

The present study utilized full-face and close up smile photographs based on the assertion of Parekh et al. ${ }^{5}$ that photographic images enable the evaluation of a given aspect or combination of elements which can be accurately and reliably modified at will. According to these authors, if a proper evaluation is to be achieved, images should be standardized by removing any elements that might distract an examiner's attention. For this reason, in all original photographs some corrections were made in order to adjust the smiles is such manner as to allow the individualization of the main variable studied, i.e., the buccal corridor.

In several studies, authors have compared photographs of smiles with different buccal corridor widths. ${ }^{5,10,14,15,23}$ Some modified the same smile by adding or removing teeth, ${ }^{5,10}$ changing the width of the teeth starting from the first maxillary premolars, ${ }^{4}$ or changing the number and transverse width of posterior teeth. ${ }^{14}$ Others compared smiles of different individuals whose lateral dark space shared no similarity, either by extracting premolars or otherwise. ${ }^{15,23}$ In this study the lateral dark space was changed by altering tooth position, starting from the upper canines, since, according to Frush and Fisher, ${ }^{10}$ although the buccal corridor can only be viewed posteriorly to the canines, the position and inclination of these teeth control their size and shape. This is due to the fact that canines play a key role in shaping the dental arch, which can be attested to when mounting teeth in a complete denture.

This study also assessed manipulated images in two views: Full-face view (FFV) and close-up view of the mouth (CUVM). The results showed no statistically significant difference between the two views $(\mathrm{p}>0.05)$. These findings corroborate the literature, ${ }^{22,25}$ showing that for the evaluation of the esthetic influence of different buccal corridor dimension, that both views, i.e., full-face view, including nose, hair, eyes, face features, etc., and close-up view, highlighting only the smile, afford the same level of perception. Likewise, Gracco et al, ${ }^{6}$ suggest that in assessing smile esthetics through photographs it would be advisable to employ images that exhibit subjects' lips only so as to keep the focus on the smile itself and avoid distractions from other facial features. Moreover, authors argue that the 
esthetic impact made by showing the teeth is reduced in FFV, thus recommending the use of full-face photos to assess smile esthetics. ${ }^{26}$

This study made use of a visual analog scale which allowed fast and straightforward measurements to be taken while streamlining and clarifying the process for the raters. This scale recently gained in popularity to measure subtle differences in dental and facial attractiveness..$^{10,13,19}$ Maple et al ${ }^{19}$ stated that grading with a continuous variable enables greater freedom in data analysis, averting bias related to preferred values, as is the case in the scale of numeric intervals.

In the past, studying smile esthetics was a more complex task since it was difficult to standardize actual models and to change the variables of interest. More recently, however, given the ability to digitally manipulate images of the same subject, changing the region of the buccal corridor and having the images assessed is a methodology that has been applied by some researchers. ${ }^{4,5,10,14}$ It is, however, essential to bear in mind that this methodology uses artificial images and should therefore not be used as a single parameter for all patients. The findings of these studies are but guidelines, and should be applied with caution, taking into account, in particular, the individual characteristics of each patient and their esthetic expectations.

\section{CONCLUSIONS}

According to the data analyzed in this study, the smiles considered most attractive were those with medium width buccal corridor. Furthermore, it was found that, in general, there was no statistically significant difference between the narrow and wide buccal corridor. In addition, analysis of the smiling images revealed no statistical differences between FFV vs. CUVM images.
1. Mondelli J. Estética e cosmética em clínica integrada restauradora. São Paulo (SP): Quintessence; 2003

2. Ong E, Brown RA, Richmond S. Peer assessment of dental attractiveness. Am J Orthod Dentofacial Orthop. 2006 Aug;130(2):163-9.

3. Ackerman MB. Buccal smile corridors. Am J Orthod Dentofacial Orthop. 2005 May;127(5):528-9.

4. Gracco A, Cazzani M, D'Elia L, Manfrini M, Peverada C, Siciliani G. The smile buccal corridors: esthetic value for dentists and laypersons. Prog Orthod. 2006;7(1):56-65.

5. Parekh S, Fields HW, Beck FM, Rosenstiel SF. The acceptability of variations in smile arc and buccal corridor space. Orthod Craniofac Res. 2007 Feb;10(1):15-21.

6. Frush JP, Fisher RD. The dynesthetic interpretation of the dentogenic concept. J Prosthet Dent. 1958 July;8(4):558-81.

7. Sarver DM, Ackerman MB. Dynamic smile visualization and quantification. Part 2: Smile analysis and treatment strategies. Am J Orthod Dentofacial Orthop. 2003 Aug;124(2):116-27.

8. Johnson DK, Smith R. Smile esthetics after orthodontic treatment with and without extraction of four first premolars. Am J Orthod Dentofacial Orthop. 1995 Aug;108(2):162-7.

9. McNamara JA. Maxillary transverse deficiency. Am J Orthod Dentofacial Orthop. 2000 May;117(5):567-70

10. Roden-Johnson D, Gallerano R, English J. The effects of buccal corridor spaces and arch form on smile esthetics. Am J Orthod Dentofacial Orthop. 2005 Mar;127(3):343-50.

11. Mendes WB, Bonfante G. Fundamentos de Estética em Odontologia. 2a ed. São Paulo (SP): Santos; 1996

12. Gianelly AA. Arch width after extraction and nonextraction treatment. Am J Orthod Dentofacial Orthop. 2003 Jan;123(1):25-8

13. Kokich VO, Kiyak HA, Shapiro PA. Comparing the perception of dentists and lay people to altered dental esthetics. J Esthet Dent. 1999;11(6):311-24.

14. Moore T, Southard KA, Casko JS, Qian F, Southard TE. Buccal corridors and smile esthetics. Am J Orthod Dentofacial Orthop. 2005 Feb;127(2):208-13.
15. Ritter DE, Gardini LG, Pinto A, Locks A. Esthetic influence of negative space in the buccal corridor during smiling. Angle Orthod. 2006 Mar;76(2):198-203.

16. Abu Alhaija ES, Al-Shamsi NO, Al-Khateeb S. Perceptions of Jordanian laypersons and dental professionals to altered smile esthetics. Eur J Orthod. 2011 Aug;33(4):450-6.

17. Isiksal E, Hazar S, Akvalçin S. Smiles esthetics: perception and comparison of treated and untreated smiles. Am J Orthod Dentofacial Orthop. 2006 Jan;129(1):8-16

18. McLeod C, Fields HW, Hechter F, Wiltshire W, Rody W, Christensen J. Esthetics and smile characteristics evaluated by laypersons: a comparison of Canadian and US data. Angle Orthod. 2011 Mar;81(2):198-205

19. Maple JR, Vig KW, Beck FM, Larsen PE, Shanker S. A comparison of providers' and consumers' perceptions of facial-profile attractiveness. Am J Orthod Dentofacial Orthop. 2005 Dec;128(6):690-6

20. Dunn WJ, Murchison DF, Broome JC. Esthetics: patients' perceptions of dental attractiveness. J Prosthodont. 1996 Sept;5(3):166-71.

21. Tedesco LA, Albino JE, Cunat JJ, Slakter MJ, Waltz KJ. A dentofacial attractiveness scale. Parte II: consistency of perception. Am J Orthod. 1983 Jan;83(1):44-6.

22. Suzuki L, Machado AW, Bittencourt MAV. Avaliação da influência da quantidade de exposição gengival na estética do sorriso. Dental Press J Orthod. 2011 Sept/ Oct;16(5):37.e1-10

23. Yang $\mathrm{IH}$, Nahm DS, Baek $\mathrm{SH}$. Which hard and soft tissue factors relate with the amount of buccal corridor space during smiling? Angle Orthod. 2008 Jan;78(1):5-11.

24. Telles D, Hollweg H, Castellucci L. Prótese Total: convencional e sobre implantes. São Paulo (SP): Ed. Santos; 2003.

25. Rodrigues CD, Magnani R, Machado MS, Oliveira OB. The perception of smile attractiveness. Angle Orthod. 2009 July;79(4):634-9.

26. Flores-Mir C, Silva E, Barriga MI, Lagravère MO, Major PW. Layperson's perception of smile esthetics in dental and facial views. J Orthod. 2004 Sept;31(3):204-9. 